was also convened. These steps have assisted adjustment of the proposed guideline to maximise flexibility, acceptability and stability; while minimising resource implications. Representativeness and the securing of government support perhaps remain the most significant challenges.

Implications Consultation with the advisory group and the wider stakeholders has been effective in developing a widely acceptable, user-friendly, low resource data form to gather useful data. Further strategies to overcome barriers will be developed over the course of the pilot study and this needs to be done in consultation the advisory group and stakeholders.

\section{THE MORTUARY AS A SOURCE OF INJURY DATA: PROGRESS TOWARDS A MORTUARY DATA GUIDELINE FOR FATAL INJURY SURVEILLANCE}

N Grills, J Ozanne-Smith*, K Bartolomeos Correspondence: Department of Epidemiology and Preventative Medicine, Monash University, Victorian Institute of Forenic Medicine, 6/157 Kent Street, Ascot Vale 3032, Australia

\subsection{6/ip.2010.029215.516}

Background Injury is a substantial and preventable public health problem accounting for $10 \%$ of deaths worldwide, of which $90 \%$ are estimated to occur in low and middle income countries (LMICs). To help bridge the obstacle of inadequate data in LMICs a simple cost effective system for mortuary surveillance of fatal injuries is being developed in consultation with the WHO. This will inform, direct and monitor injury prevention interventions and policies in LMICs. There are many challenges to the establishment of an international guideline for mortuary data surveillance and this article seeks to outline the process, challenges and progress.

Methodology This article uses CDCs attributes of a successful surveillance system to characterise barriers anticipated in guideline development and discuss the way forward.

Conclusions The development of a mortuary data guideline has proceeded and overcome various barriers. The consultative process generated feedback from key stakeholders including forensic pathologists, Ministry of Health officials and injury prevention experts. An International Advisory Group 